\title{
The potential benefit of omega-3 fatty acid capsule on Mean platelet volume and Platelet count in type-2 Diabetes Mellitus
}

Tamanna Binte Habib ${ }^{*}$, Qazi Shamima Akhter², Hasan Imam³ ${ }^{3}$ Nahid Yeasmin ${ }^{4}$, Sharmin Nahar ${ }^{5}$, Farhana $\operatorname{Rahman}^{6}$

\begin{abstract}
:
Background: Diabetes Mellitus (DM) is a major non-communicable health problem that has effects on glycemic status. Hyperglycemia that is an inherent finding of diabetes causes platelet dysfunction. Oral omega-3 fatty acid supplementation may improve glycemic status in diabetic patient and reduce micro and macrovascular complications.
\end{abstract}

Objective: To observe the effect of supplementation of omega-3 fatty acid on Mean Platelet Volume (MPV) and Platelet count in type 2 DM.

Methods: A prospective interventional study was conducted from January 2017 to December 2017. A total numbers of 52 diagnosed type 2 diabetic patients of both sexes were selected within age 40 to 50 years. Among them, 27 type 2 diabetic patients with supplementation of omega 3 fatty acid (2g/day) for 12 weeks were considered as study group and another 25 type 2 diabetic patients without supplementation of omega 3 fatty acid were considered as control group. The study subjects were selected from Outpatient Department of Endocrinology, Dhaka Medical College Hospital, Dhaka and personal contact from Dhaka city. MPV and platelet count were measured by hematology analyzer. The study parameters were measured at base line and after 12 weeks of study period in both groups.

Results: In this study MPV and platelet count levels were significantly lower $(p<.001)$ in diabetic patients after supplementation with omega-3 fatty acid in comparison to that of their baseline value. Again, after 12 weeks, $M P V$ and platelet count were significantly lower $(p<.001)$ in diabetic patients after supplementation with omega-3 fatty acid in comparison to control group. In control group, MPV and Platelet count were almost similar both at baseline and after 3 months of follow-up.

Conclusion: After analyzing the results of the study it can be concluded that omega-3 fatty acid may improve MPV and Platelet count levels in type 2 diabetic patients and may be helpful to minimize the complications of type-2 DM.

Keywords: DM, MPV, Platelet count and Omega-3 fatty acid.

\section{Introduction:}

DM is a group of metabolic disease characterized by hyperglycemia resulting from defect in insulin secretion or insulin action or both. The chronic hyperglycemia of diabetes is associated with long term damage, dysfunction and failure of various organs especially the eyes, kidneys, nerve, heart and blood vesse ${ }^{1}$. Diagnostic criteria of DM are fasting plasma glucose level $\geq 7.0 \mathrm{mmol} / 1(126 \mathrm{mg} / \mathrm{dl})$ or plasma glucose 2 hours after an oral glucose $\geq 11.1 \mathrm{mmol} / \mathrm{L}(200 \mathrm{mg} / \mathrm{dl})$ and HbAlc $\geq 6.5 \%{ }^{2}$. The prevalence of Type 2 Diabetes Mellitus (T2DM) is expected to rise from 285 million in 2010 to 438 million by the year of $2030^{3}$. Within 2030, the prevalence of DM will be 11.1 million in Bangladesh ${ }^{4}$.

MPV is machine generated average size of platelet whose value is enhanced in subjects with DM. Larger platelet is enzymatically more active that results thrombogenesis. In Diabetes mellitus, there are larger platelets than normal in circulating blood. When hyperglycemia occurs, osmotic swelling occurs in platelet that raises MPV and also increases platelet turn over rate. Elevation of MPV and platelet count is considered as independent risk factor for thromboembolism ${ }^{5}$.
Insulin is a potent anabolic hormone which is essential for appropriate tissue development, growth and maintenance of whole body glucose homeostasis. Insulin regulates glucose homeostasis by increasing the rate of glucose uptake into striated muscle and adipose tissue. In skeletal muscle, insulin prompts glucose uptake by stimulating translocation of GLUT-4 to plasma membrane ${ }^{6}$. Insulin resistance occurs when the insulin sensitive tissue loses response to insulin. The basic effect of insulin resistance on glucose metabolism is to prevent the uptake and utilization of glucose by most cells of the body. As a result blood glucose concentration increases, cell utilization of glucose falls, utilization of fat increases and free fatty acid level increases in blood ${ }^{7}$.

Omega-3 Fatty acids are a group of polyunsaturated fatty acids, consist of alpha linolenic acid (ALA), eicosapentaenoic acid (EPA) and docosahexanoic acid (DHA). They are found in seafood including fatty fish (e.g. salmon, tuna and trout) and shellfish (e.g. crab, mussels and oysters). They also increase insulin sensitivity, help in blood clotting, promote fat digestion, improve fertility, act as a mood elevator and help in brain development ${ }^{8}$. 
Consumption of fish oil can decrease free fatty acid level, improve insulin sensitivity as well as reduce the incidence of $\mathrm{T}_{2} \mathrm{DM}^{9}$. Poly unsaturated fatty acid acts directly on insulin sensitive tissues, increases number of insulin receptors thus reduces insulin resistance ${ }^{10}$. Omega- 3 fatty acid facilitates the action of insulin through various metabolic pathways and improves glycemic status in type-2 DM. It also facilitates the action of insulin through suppression of hepatic lipogenesis and reduces the release of Triglyceride (TG) from liver and oxidation of fatty acids in liver, thus reduces the complications in $\mathrm{T}_{2} \mathrm{DM}^{11}$. Omega-3 fatty acid prevents this change by increasing peroxisome proliferator receptor gamma, increasing hepatic uptake and oxidizing free fatty acid in skeletal muscle ${ }^{12}$. Some author found significant reduction in serum fasting blood sugar and $\mathrm{HbA}_{1} \mathrm{C}$ levels in diabetic patient those are supplemented with fish oil ${ }^{13}$. Omega-3 fatty acid acts on component of platelet (thromboxine A2) and reduces MPV and platelet count. ${ }^{14}$ Supplementation of fish oil may improve glycemic status and reduce MPV and platelet count in diabetic patients.

As there is fewer published data available regarding this topic in our country, this study has been designed about the supplementation of omega-3 fatty acid on MPV and platelet count in Bangladeshi type-2 DM patients. It is expected that findings of this study will be helpful for better management and its complication.

\section{Methods:}

This prospective, interventional study was done in the Department of Physiology, Dhaka Medical College from January 2017 to December 2017. The research work was carried out after obtaining ethical clearance from concerned departments, Research Review Committee and Ethical Review Committee of Dhaka medical college, Dhaka. The patients were selected from outpatient department of Endocrinology, Dhaka medical college and personal contact from Dhaka city. At the Beginning of this study, 60 diagnosed

1. Lecturer, Department of Physiology, Dhaka Medical College, Dhaka.

2. Professor \& Head, Department of Physiology, Dhaka Medical College, Dhaka.

3. Graded Specialist, Department of Anesthesia, Combined Military Hospital, Bogra.

4. Assistant Professor, Department of Physiology, Dhaka Medical College, Dhaka.

5. Lecturer, Department of Physiology, Dhaka Medical College, Dhaka.

6. Lecturer, Department of Physiology, Dhaka Medical College, Dhaka.

\section{*Corresponding author:}

Tamanna Binte Habib, Lecturer, Department of Physiology, Dhaka Medical College, Dhaka.

E-mail: tamannapompy1234@gmail.com or hshimu109@gmail.com Qazi Shamima Akhter, Professor \& Head, Department of Physiology, Dhaka Medical College, Dhaka.

E-mail:shamimaqazi@yahoo.com type II diabetic patients were randomly selected on the basis of exclusion and inclusion criteria. There were 30 patients in control group and 30 patients in study groups, recruited for completion of study. After 6 weeks of study period, 3 patients were dropped out from study group and 5 patients were dropped out from control group. Inclusion Criteria: Total 52 type II diabetic patient of both sexes with the age ranging from 40-50 years with FBG $7.0 \mathrm{mmol} / \mathrm{l}$ or $126 \mathrm{mg} / \mathrm{dl}$, HbA1c $6.5 \%$, serum Total Cholesterol (TC) $200 \mathrm{mg} / \mathrm{dl}$, serum TG 150 $\mathrm{mg} / \mathrm{dl}$, Body Mass Index (BMI) $\leq 30 \mathrm{Kg} / \mathrm{m}^{2}$ were included in this study. Exclusion Criteria: Subjects with history of heart, liver, endocrine disorder, thromboembolism, coagulation disorder, on insulin therapy, anti-coagulant and anti-platelet drugs and pregnant women were excluded from this study. For this study, 27 diagnosed type- 2 diabetic patients with omega-3 fatty acid supplementation were selected as study group and 25 type- 2 diabetic patients without oral omega-3 fatty supplementation were selected as control group. The study group was again sub-divided into pre-supplementation group and after 12 weeks of supplementation as post supplementation group. The control group was sub-divided as pre and post follow-up group. After selection, the nature, purpose and benefits of the study were explained to each subject and informed written consent was taken from participants. Before taking blood sample, detailed family and medical history were taken. Anthropometric measurement of the subjects was recorded and blood pressure was measured. All the information was recorded in a data schedule. With aseptic precaution, $5 \mathrm{ml}$ of venous blood was collected from ante-cubital vein by a disposable plastic syringe from each subject after overnight fasting for biochemical tests. MPV and platelet count were estimated by Mindray BC-5380 hematological automated 5 part cell counter in department of Laboratory Medicine, Dhaka Medical College Hospital, Dhaka. Omega-3 fatty acid (2gm) was supplied to the study group. Then they were asked to consume twice daily for 12 weeks with proper instructions. Subjects were instructed not to change their diet and physical activity during the course of the study. A regular telephonic contact and periodic visit were made to the participants. For statistical analysis, Paired Student's' $t$ ' test and Unpaired Student's ' $t$ ' test were performed as applicable using Statistical Package for Social Scientists (SPSS) for windows version 16.0. Data were expressed as mean $\pm \mathrm{SD}$. The $p$ value of $<0.05$ was accepted as level of significance.

\section{Results}

In this study, no significant difference was observed in age, sex, BMI, systolic and diastolic blood pressure between study and control group (Table 1). The MPV and platelet count levels were almost similar and no statistical difference was observed at the beginning of the study. In study group, MPV $(\mathrm{p}<.0 .001)$ and platelet count $(\mathrm{p}<.0 .001)$ levels were found significantly lower in post supplementation group than pre-supplementation group. Again the MPV $(\mathrm{p}<.0 .001)$ and platelet count $(\mathrm{p}<0.001)$ levels were found significantly lower in study group compared to control group. In control group, there was no significant difference in MPV and platelet count between pre and post follow-up group (Table 2). 
Table 1: General characteristics of the patients in both groups $(\mathrm{N}=52)$

\begin{tabular}{lccc}
\hline Parameters & $\begin{array}{c}\text { Study group } \\
(\mathrm{n}=27)\end{array}$ & $\begin{array}{c}\text { Control group } \\
(\mathrm{n}=25)\end{array}$ & $\begin{array}{c}\text { V Value } \\
\text { Age (years) }\end{array}$ \\
Sex $(\%)$ & $45.90 \pm 3.80$ & $44.92 \pm 3.75$ & 0.354 \\
Male & $18(66.7 \%)$ & $11(44 \%)$ & 0.100 \\
Female & $9(33.3 \%)$ & $14(56 \%)$ & 0.114 \\
BMI $\left(\mathrm{kg} / \mathrm{m}^{2}\right)$ & $25.03 \pm 2.27$ & $25.87 \pm 1.75$ & 0.104 \\
Systolic BP $(\mathrm{mmHg})$ & $119.07 \pm 7.08$ & $121.79 \pm 4.47$ & 0.764 \\
Diastolic BP (mmHg) & $79.63 \pm 6.26$ & $80.00 \pm 0.00$ & 0.852 \\
Duration of disease (years) & $5.43 \pm 1.50$ & $5.35 \pm 1.57$ & \\
\hline
\end{tabular}

Table 2 : Mean Platelet Volume (MPV) and Platelet count levels in different groups ( $\mathrm{N}=52)$

\begin{tabular}{lcccc}
\hline Parameters & $\begin{array}{c}\text { Study group } \\
(\mathrm{n}=27)\end{array}$ & $\mathrm{p}$ Value & $\begin{array}{c}\text { Control group } \\
(\mathrm{n}=25)\end{array}$ & $\mathrm{p}$ Value \\
\hline & Pre-suppl & Post-suppl & Pre-follow-up & Post follow-up \\
MPV(fl) & $11.13 \pm 2.28$ & $9.64 \pm 1.65$ & $.00111 .23 \pm 2.21$ & $11.31 \pm 1.56 .746$ \\
Platelet count (lakhs) & $2.82 \pm 0.981 .64 \pm 1.04$ & .001 & $2.76 \pm 1.09$ & $2.71 \pm 1.07 .669$ \\
\hline
\end{tabular}

\section{Discussion:}

In this study, MPV and platelet count were significantly lower in patients with T2DM after supplementation with omega-3 fatty acid in comparison to that of their baseline value. Again, after 12 weeks, mean platelet count levels were significantly lower in type-2 diabetic patients supplemented with omega- 3 fatty acid in comparison to that of diabetic control group without omega-3 fatty acid. Almost similar results were observed by different researchers of different countries ${ }^{15-18}$. On the contrary, there was no significant difference in MPV and platelet count in patients after supplementation of omega-3 fatty acid in comparison to that of their baseline values and diabetic control group who were not supplemented with omega-3 fatty acid ${ }^{19}$. There was a history of less physical activity in the study subjects that might contribute to the result of that study. Literature review suggested that, when hyperglycemia occurs, it results in osmotic swelling of platelet and also increases its number. Omega-3 fatty acid decreases the risk of thrombosis by inhibiting thromboxin $\mathrm{A}_{2}$ synthesis and acts as an antagonist of pro-aggregatory $\mathrm{TXA}_{2} \mathrm{PGH}_{2}$ receptor in human platelet ${ }^{19}$. Omega-3 fatty acid acts on TG level in diabetes, when triglyceride level rises, it decreases the binding of insulin with its receptor through releasing some inflammatory mediator from liver that decreases insulin receptor signaling activity. Omega-3 fatty acid has a role on reducing serum TG level. Peroxisome proliferator receptor- $\alpha$ exists in the liver that is increased in number in presence of omega-3 fatty acid. An increase in PPAR- $\alpha$ leads to hepatic uptake of free fatty acid. It also increases the free consequence of free fatty acid reduction helps to decrease TG synthesis. Thus, omega-3 fatty acid reduces serum TG level that facilitates the binding of insulin to its receptor and improves insulin sensitivity ${ }^{20}$.
In this study, MPV and platelet count levels decrease in patients with T2DM after supplementation of omega-3 fatty acid in comparison to their baseline value and control group. Omega-3 fatty acid supplementation increases free fatty acid oxidation, thus it decreases serum TG level, that helps to rise insulin sensitivity so platelet count and volume remain altered and it is also decreased by suppressing thromboxin $A_{2}$ synthesis and acts as an antagonist of pro-aggregatory $\mathrm{TXA}_{2} \mathrm{PGH}_{2}$ receptor in human platelet. This reduces the thrombosis and complication in diabetic patient ${ }^{21}$.

\section{Conclusion:}

After analyzing the results of this study, it can be concluded that supplementation of omega-3 fatty acid can reduce MPV and platelet count levels in patients with T2DM. Therefore, omega-3 fatty acid containing food may be helpful to minimize the complications in T2DM.

\section{Conflict of Interest:}

There is no conflict of interest. Any part of the study has ever been presented or published anywhere.

\section{Acknowledgement}

The authors are thankful to the study subjects for their active, sincere and voluntary participation.

\section{References}

1. American Diabetes Association. Diagnostic and classification of DM. Diabetes Care 2017; 40(1):11-24

2. World Health Organization. Definition and diagnosis of DM and intermediate hyperglycemia: Report of a WHO/IDF. Consultation. [Internet].Geneva: World Health Organization; 2011. [Cited 2017 May 18].Available from; https;//www.idf.org. 
3. Ramachandran A, Snehalata C, Shetty S, Nandita A.Trends in prevalence of diabetes in Asian countries. World J of Diabetes 2012; 3(6):110-117.

4. Baynest HW. Classification, pathophysiology, diagnosis and management of DM. J of Diabetes Metab 2015; 6(541):1-13.

5. Kaur N, Bhat S, Hussain S, Singh K, Thukral S, Reddy A.. Bleeding time, Clotting time, Mean platelet volume and Platelet count in type-2 Diabetes Mellitus-A case control study.Int. J of Med Sci and curr res 2018;1(3):141-146.

6. Pessin JF and Saltiel S. Signaling pathways in insulin action: molecular targets of insulin. The J of Clin invest2000; 106 (2): 155-169.

7. Delarue J , Magnan C. Free acids and insulin resistance. Research Gate $2014 ; 10(2): 142-8$

8. National Center for Complementary and Integrative Health n.d., Omega-3 supplements in depth. [Internet] 2017[Cited on April 23]2017. Available from: http:// nccih.nih.gov//omega-3 supplements in depth/html

9. Albert BB, Derraik JGB, Brenan CM, Smith GC, Glarg ML, Smith $\mathrm{DC}$ et al.Higher omega-3 index is associated with increased insulin sensitivity and more favourable metabolic profile in middle-aged overweight men.Sci Rep 2014;4:6696.

10. Laila AZ, Lanza IR. Insulin-Sensitizing effects of omega-3 fatty acids: lost in translation?.Nutrients. 2016;8 (329) :1-24.

11. Lopez AL, Ramos RV, Carrillo BE. Type 2 Diabetes, PUFAs and vitamin D: their relation to inflammation. J ofImmun Res 2014; $1: 1-14$.

12. Flachs P, Rossmeisl M, Kopecky J. The effect of n-3 Fatty Acids on Glucose Homeostasis and Insulin Sensitivity.Physiol Res 2013; 63(1): 93-98.

13. Ellulu MS, Khazai H, Patimah I, Rahmat A .Effect of long chain omega-3 polyunsaturated fatty acids on inflammation and metabolic markers in hypertensive and/or diabetic obese adults: a randomized control trial. Food \& Nut Res 2017;60(1) :1-9.
14. Di Nicolantonio JJ, Okeefe J. Importance of maintaining a low omega-6 /omega-3 ratio for reducing platelet aggregation, coagulation and thrombosis. Open Heart 2019;6:e 001011.doi:10.1136.

15. Udupa A, Nahar P, Shah S, Shirsagar K , Ghongane B .A comparative study of effects of omega 3 fatty acids, alpha lipoic acid and vitamin E in type 2 DM. Ann Med Health Sci Res 2013;3(3):442-6.

16. Zambon S, Friday KE, Childs MT, Fujimoto WY, Bierman EL,EnsinckJW.Effect of glyburide and $\omega 3$ fatty acid dietary supplements on glucose and lipid metabolism in patients with non-insulin-dependent DM. Am J of ClinNutr 1992;56(2):447-54.

17. Thota RN, Acharya SH, Abbott KA. Curcumin and long chain omega-3 polyunsaturated fatty acids for prevention of type-2 diabetes.Trials2016; 17(565):1-11.

18. Mahmoodi MR, Kimiagar M, MehrabiY.The effect of omega-3 plus vitamin $\mathrm{E}$ and zinc plus vitamin $\mathrm{C}$ supplementation on cardiovascular risk markers in postmenopausal women with type-2 diabetes. TherAdvEndocrinolMetab2014; 5(4): 67-76.

19. Virtanen KJ, Mursu J, VoutilainenS,UustupaM,Tuomainen TP.Serum Omega-3 Polyunsaturated Fatty Acids and Risk of Incident Type 2 Diabetes in Men. Diabetes Care 2014:37(1):186-196

20. Shidfar F, Keshavaraz A, Hosseyni S, Ameri A. Effect of omega -3 fatty acid supplements on serum lipids, apo-lipopotein and malondehyde in type 2 diabetes patient. East Mediterranean Health J 2008;14(2):305-12.

21. Kromhout D, Yasuda S, Shimokawa H.Fish oil and omega-3 fatty acid in cardiovascular disease. Eur Heart J 2012;33(4):436-443. 